\title{
Clinical features, course and treatment of methamphetamine-induced psychosis in psychiatric inpatients
}

\author{
Homa Zarrabi, Mohammadrasoul Khalkhali', Azam Hamidi, Reza Ahmadi and Maryam Zavarmousavi
}

\begin{abstract}
Background: Over the past few years, methamphetamine-induced psychosis (MIP) has increased in Iran, accounting for a significant percentage of psychiatry hospital admissions. The present study was conducted with an aim to investigate clinical symptoms, and course and treatment methods of MIP inpatients in Shafa Psychiatry Hospital in northern Iran.

Methods: Participants were 152 MIP inpatients. Brief Psychiatric Rating Scale (BPRS) subscales of suspiciousness, unusual thought content; hallucinations and hostility were used to measure psychiatric symptoms. Data regarding suicide and homicide and violence were also obtained through interviews with the inpatients and their family. Based on their lengths of recovery time, the inpatients were categorized into 3 clinical groups. These inpatients received their usual treatments and were monitored for their psychiatric symptoms and clinical course of illness. The data were analyzed by descriptive statistics.

Results: The most frequent psychiatric symptoms were violence (75.6\%), intimate partner violence (61.2 \%), delusions of persecution ( $85.5 \%$ ), delusions of reference (38.5\%), delusions of grandiosity (32.9\%), delusions of infidelity (30.2\%), auditory hallucinations (51.3\%), visual hallucinations (18.4\%), suicidal thoughts (14.5\%), homicidal thoughts (3.9\%), suicide attempts (10.5\%) and homicide attempts (0.7 \%). Recovery from psychotic symptoms in $31.6 \%$ of the inpatients took more than one month. $46.1 \%$ of the inpatients were treated with Risperidone and $37.5 \%$ with Olanzapine. Persecutory delusion and auditory hallucination were the most frequent persistent psychotic symptoms. $20.8 \%$ of the inpatients with duration of psychosis more than one month were treated with electroconvulsive therapy (ECT) along with antipsychotics.
\end{abstract}

Conclusion: All forms of violence are highly frequent in MIP inpatients. Our finding agrees with many other studies suggesting that recovery from MIP can take more than a month. Initial promising findings were found regarding the efficacy of Electroconvulsive therapy in MIP patients.

Keywords: Methamphetamine, Psychotic disorders, Inpatients, Violence

\section{Background}

Acute psychotic disorder is a common phenomenon in the abuse of amphetamines and methamphetamine, and one of the most important reasons for referring to and hospitalization in emergency or psychiatric wards [1-3]. The psychotic symptoms in acute intoxication are persecutory, influence and control delusions, auditory, visual

\footnotetext{
*Correspondence: khalkhali@gums.Ac.Ir

Department of Psychiatry, Shafa University Hospital, Guilan University of

Medical Sciences, Panzdah Khordad Ave., 4165863795 Rasht, Iran
}

and tactile hallucinations, and a tendency toward violence [4-6]. In certain cases, even after the symptoms of intoxication disappear and the substance abuse is not repeated, these symptoms are seen again in prolonged manners. These symptoms cannot be differentiated from other psychotic symptoms of schizophrenia spectrum disorders [4-9].

Acute psychosis induced by amphetamines is limited to a maximum period of 4 to 5 days after the intoxication, and appears to resolve with abstinence; although the recovery may be incomplete [9]. Japan is the origin 
of methamphetamine. This country has experienced several major epidemics of the substance. Japanese psychiatrists believe that stimulants-induced psychosis can be divided into different clinical groups. The first group is the transient psychosis group in which the incidence and duration of symptoms are limited to a maximum period of 4 to 5 days after the intoxication, which can be seen in the withdrawal or intoxication periods. In the second group, psychotic symptoms can be resolved in less than a month $[7,8]$. In the third group, symptoms could be of much longer duration of up to several months, or of several years [7-10]. Some experts believe that 5 to $10 \%$ of the MIP patients may not fully recover from their psychotic symptoms even after a long time $[7,8]$. The studies recently carried out as well as those in Iran have provided strong clinical evidence to support such a classification $[6,7,11,12]$. In Yui K et al. [7] study, $64 \%$ of patients recovered from their symptoms within ten days, and $82 \%$ gained full recovery within a month, and in 18 $\%$, psychosis persisted more than a month. In a previous study in Iran, $8.75 \%$ of the cases with MIP had symptoms that continued more than a month [6]. In the 3 major epidemics in Japan, a significant number of patients still had the psychotic symptoms after a month $[7,8]$. Some researchers believe that MIP can imitate both positive and negative symptoms of schizophrenia, and some consider it, a short-term psychosis with positive symptoms. It is difficult to distinguish the Japanese persistent psychosis from a primary psychosis like schizophrenia triggered by the use of amphetamines [9, 12].

There are still many unanswered questions regarding clinical characteristics of MIP. Unfortunately, Iran has experienced an epidemic of methamphetamine use in recent years, which has provided an opportunity to study clinical symptoms, and course and treatment methods of MIP inpatients.

\section{Methods}

This cross sectional study was conducted at Shafa Psychiatry Hospital, the only psychiatric hospital, referral and psychiatric emergencies center in Rasht, the capital of Guilan Province, with a population of 2.5 million, in northern Iran, from August 2013 to August 2014.

Participants were 152 MIP inpatients who were admitted to Shafa Hospital due to clinically significant symptoms of hostility, grandiosity or suspiciousness according to a score of 5 or above, and hallucinations, unusual thought content or suicidality according to a score of 6 or above on the Brief Psychiatric Rating Scale (BPRS) [13]. The hostility in the month preceding admission was considered violence. The urine screening tests for detecting amphetamines, morphine and cannabis were performed at the time of admission in the emergency ward. The patients were interviewed about their drug and substance abuse and dependency. The family observations of intoxication periods and substance related behaviors in the preceding month of admission were obtained in separate face-to-face interviews and were used to determine the abuse of any probable substances. The medical records were used to determine schizophrenia, bipolar disorder, antisocial and borderline personality disorder. If positive urine tests or any history of abuse of alcohol, cannabis or morphine in the preceding month of admission was detected or if the patients were diagnosed with any of the above-mentioned primary psychiatric disorders, they were excluded from the study. Fixed doses of methadone were accepted. All of the patients of this study had positive urine tests for methamphetamine. A psychiatrist evaluated the patients and concluded that they met the DSMIV-TR diagnostic criteria for amphetamine-like use disorders (dependence; 304.40 or abuse; 305.70 ) and amphetamine-like induced psychotic disorders (292.11, 292.12).

BPRS was administered according to the guidelines provided by Lukoff [13] at admission time and then twice weekly to assess psychiatric symptoms and to monitor the patients' improvement. After the patients were admitted to the psychiatric wards and the primary evaluations were completed, treatment was undertaken by certified psychiatrists. The inpatients were monitored for primary psychiatric symptoms and clinical course of treatment, and they received usual evaluation and treatment for psychotic disorders. There was no intervention or compromise regarding treatment methods, whether medicinal or otherwise. In order to be able to compare the results of this study with other studies, considering the patterns of recovery of patients in the previous studies, we divided the patients in into 3 clinical groups:

Group 1 (full recovery equal or less than one week), Group 2 (full recovery more than one week but equal or less than one month), and Group 3 (full recovery more than one month). Considering that there is no global agreement and clear definition for the terms "transient" and "persistent", we preferred to use numbered groups in this paper. Achieving a score of 3 or lower in any of the mentioned subscales was the criteria for the inpatient's recovery in that particular subscale, and full recovery was determined by recovery in all of the subscales of BPRS. BPRS is a tool developed for assessing the degree of severity of psychiatric symptoms and is widely used in clinical and research assessments, and enjoys a high degree of inter-rater reliability when used by skilled clinical specialists. Certified psychiatrists and an experienced clinical psychologist who had been trained in all aspects of the interviewing skills, conducted interviews.

Data regarding suicide, homicide and violence were also obtained from interviews with the inpatients and 
their family by certified psychiatrists and a clinical psychologist, as well as from other referral sources and, if necessary, from local investigations by social workers. We asked the family members whether the patients had assaulted them with no harm repeatedly, for example, slapped or pushed them, whether the patients had severely destroyed the properties in the house or outside, for example, knocked over furniture, broken windows, and burned things, or whether the patients had assaulted them with definite possibility of harming or with actual harm, for example, assaulted them with a hammer or a knife? In this study, we only considered sever physical violence.

While hospitalized, we monitored the inpatients closely, regarding abuse of illicit drugs and substances every 3 days, using clinical evaluation and urine screening tests. Inpatients who did not continue with the treatment or, for any reason, tested positive for any substance abuse during the hospitalization period were excluded from this study.

The written consents were obtained both from the patient and from a responsible (legally authorized) family member in each case. This study received ethics approval from the Research Ethics Committee of Guilan University of Medical Sciences (IR.GUMS.REC.1394.253). The data were analyzed by SPSS-15. The Chi-Square test was used for statistical analysis, and values less than 0.05 were considered meaningful.

\section{Results}

Out of 2600 Shafa Hospital admissions from August 2013 to August 2014, 1173 patients had positive urine tests for methamphetamine. Eventually 152 MIP inpatients formed the sample of this study and the others were excluded due to exclusion criteria. Table 1 shows the demographic characteristics of our study. The average age of the population was 35.7 (8.07) years of age, with the highest frequency in the 30-40 year age group.

Table 2 shows the clinical characteristics of our study. 115 of the inpatients $(75.6 \%)$ had at least one form of violent behavior in the past month. Of the 49 married inpatients, 30 married inpatients (61.2 \%) displayed intimate partner violence. It must be noted that a person may have multiple aggressive behaviors; therefore, the statistics yielded various answers. 146 of the inpatients $(96.1 \%)$ had delusions or hallucinations. 6 of the patients (3.9\%) showed no symptoms of delusions or hallucinations at the time of admission, but they were hospitalized for disorganized behaviors. No statistically meaningful relation was found between psychotic symptoms (delusions and hallucinations) and different forms of violence. The only significant statistical difference was found between intimate partner violence and delusions of reference $(p<001)$. Persecutory delusion and auditory hallucination were the most frequent persistent psychotic symptoms. The frequencies of grandiosity delusion $(p<0.01)$ and auditory hallucination $(p<0.05)$ were significantly different in clinical groups (Table 2).

Table 3 shows the relation between the treatment methods and clinical groups. The patients were treated with antipsychotics, supportive therapy and ECT (Electroconvulsive Therapy). Serotonin- Dopamine Antagonists, especially Risperidone, (46.1 \%) and Olanzapine (37.5 \%) were the most frequently prescribed antipsychotics. The use of typical antipsychotics was significantly low. Table 4 shows the frequency of the use of antipsychotic drugs in different clinical groups.

\section{Discussion}

Methamphetamine is the second most frequently abused illicit drug in Iran $[11,14]$ and many individuals who referred to psychiatric emergency wards abused methamphetamine [1]. Among those admitted, other substances usually accompany methamphetamine abuse, which makes it difficult to relate psychiatric symptoms to one particular substance. Due to the exclusion criteria in the present study, it may be claimed that this study can provide a more accurate account of psychiatric symptoms connected with methamphetamine abuse $[3,5]$.

Like other studies, persecutory delusion and auditory hallucination were the most frequent psychiatric symptoms, and almost all inpatients had experienced a few psychiatric symptoms. These symptoms, along with delusion of reference, grandiosity delusion and delusions of infidelity to the spouse can hardly be differentiated from other primary psychotic disorders such as schizophrenia [15-17]. In addition, delusion of grandiosity and aggression can be frequently seen in manic episodes of bipolar disorder.

In comparison with the previous study conducted in Iran, the average age of the population was a little higher (35.7 vs. 30.44 ), and an approximately two-fold increase

Table 1 Demographic characteristic of 152 MIP inpatients

\begin{tabular}{|c|c|c|c|c|c|}
\hline \multicolumn{6}{|l|}{ Variables } \\
\hline Age (year) & $\mathrm{N}(\%)$ & $19-3033(21.7)$ & $31-4075(49.3)$ & $41-5034(22.4)$ & $>5010(6.6)$ \\
\hline Gender & N (\%) & Male 139 (94.1) & Female 13 (8.6) & & \\
\hline Marital status & N (\%) & Married 49 (32.2) & Single 103 (67.8) & & \\
\hline Education & N (\%) & Illiterate 12 (7.8) & $<$ High school 119 (78.3) & High school 20 (13.2) & University graduate 1 (0.7) \\
\hline
\end{tabular}


Table 2 The frequency of psychiatric symptoms in 152 MIP inpatients

\begin{tabular}{|c|c|c|c|c|c|}
\hline & ${ }^{\mathrm{a}}$ Group1N (\%) & ${ }^{\mathrm{b}}$ Group 2 N (\%) & ${ }^{\mathrm{c} G r o u p 3 ~ N ~(\%) ~}$ & Total N (\%) & $* P$ \\
\hline \multicolumn{6}{|l|}{ Delusions/hallucinations } \\
\hline Persecutory & 16(94.1) & $75(86.2)$ & 39(81.3) & 130(85.5) & 0.469 \\
\hline Reference & $9(52.9)$ & 29(33.3) & $21(43.8)$ & $59(38.8)$ & 0.221 \\
\hline Grandiosity & $1(5.9)$ & $27(31)$ & $22(45.8)$ & $50(32.9)$ & 0.008 \\
\hline Infidelity & $6(35.3)$ & 26(29.9) & $14(29.2)$ & $46(30.2)$ & 0.862 \\
\hline Thought broadcasting & $1(5.9)$ & $0(0)$ & $1(2.1)$ & $2(1.3)$ & 0.083 \\
\hline Thought insertion & $0(0)$ & $0(0)$ & $1(2.1)$ & $1(0.7)$ & 0.428 \\
\hline Thought withdrawal & $1(5.9)$ & $0(0)$ & $1(2.1)$ & $2(1.3)$ & 0.083 \\
\hline Somatic delusion & $1(5.9)$ & $2(2.3)$ & $4(8.3)$ & $7(4.6)$ & 0.196 \\
\hline Auditory hallucinations & $11(64.7)$ & $37(42.5)$ & $30(62.5)$ & 78(51.3) & 0.041 \\
\hline Visual hallucinations & $2(11.8)$ & 14(16.1) & $12(25)$ & $28(18.4)$ & 0.349 \\
\hline Tactile hallucinations & $1(5.9)$ & $0(0)$ & $1(2.1)$ & $2(1.3)$ & 0.083 \\
\hline \multicolumn{6}{|l|}{ Violence } \\
\hline$I P V^{* *}$ & $4(23.5)$ & $21(24.1)$ & $6(12.5)$ & $31(20.4)$ & 0.241 \\
\hline Family & $9(52.9)$ & $50(57.5)$ & $25(52.1)$ & $84(55.3)$ & 0.839 \\
\hline Others & $8(47.1)$ & $64(73.6)$ & $33(68.8)$ & $91(69.1)$ & 0.097 \\
\hline \multicolumn{6}{|l|}{ Suicide /Homicide } \\
\hline Suicidal thought & $2(11.8)$ & $9(10.3)$ & $11(22.9)$ & $22(14.5)$ & 0.142 \\
\hline Suicide attempt & $2(11.8)$ & $8(9.2)$ & $6(12.5)$ & $16(10.5)$ & 0.738 \\
\hline Homicidal thought & $0(0)$ & $4(4.6)$ & $2(4.2)$ & $6(3.9)$ & 1.000 \\
\hline Homicide attempt & $0(0)$ & $0(0)$ & $1(2.1)$ & $1(0.7)$ & 0.428 \\
\hline
\end{tabular}

a: Full recovery equal or less than one week

b: Full recovery more than one week but equal or less than one month

c: Full recovery more than one month

*Pearson chi square and for table with at least 1 cell expected count less than 5 , Fisher's exact test. $p<0.05$ considered significant

** Intimate partner violence

in the number of female inpatients ( $8.6 \%$ vs. $4.5 \%)$ was cited [6]. The percentage of improvement of the symptoms in the first week was the same, but the persistence of the symptoms over one month was significantly higher in our study (31.6 \% vs. $8.75 \%$ ). This means that methamphetamine takes a huge toll on the health care system. On the one hand, not only has there been no decrease in the rate of mood disorders and schizophrenia and other psychotic disorders and substance-related disorders, but the health care system is also faced with a phenomenon that has caused a majority of beds in psychiatric hospitals and emergency wards to be occupied.

The findings of our study are more in line with the Japanese studies which reported the rates of persistent psychosis in the 3 epidemics in Japan as 23, 18 and 41 respectively [6]. This may of course have been partly due to our sampling methods, since the probability of psychosis induced by non-amphetamine substances and primary psychotic disorders in our group have been reduced to a minimum. It is also probable that our

Table 3 The frequency of prescription of antipsychotics in treating MIP inpatients

\begin{tabular}{llllllll}
\hline & & Risperidone & Olanzapine & Quetiapine & Aripiprazole & Haloperidol & Perphenazine \\
\hline${ }^{a}$ Group 1 & $\mathrm{N}(\%)$ & $9(65.2)$ & $5(31.3)$ & $1(6.25)$ & $0(0)$ & $1(6.25)$ & $0(0)$ \\
${ }^{\mathrm{b}}$ Group 2 & $\mathrm{N}(\%)$ & $38(44.2)$ & $38(44.2)$ & $7(8.2)$ & $3(3.4)$ & $0(0)$ & $0(0)$ \\
${ }^{\mathrm{c}}$ Group 3 & $\mathrm{N}(\%)$ & $23(48)$ & $13(27.1)$ & $3(6.2)$ & $8(16.6)$ & $0(0)$ & $1(2.4)$ \\
\hline
\end{tabular}

a: full recovery equal or less than one week

b: full recovery more than one week but equal or less than one month

c: full recovery more than one month 
Table 4 The frequency of methods used to treat 152 MIP inpatients

\begin{tabular}{|c|c|c|c|c|c|}
\hline & & Supportive therapy & Antipsychotics & ECT* & Antipsychotics and ECT \\
\hline${ }^{a}$ Group 1 & N (\%) & $1(5.9)$ & $16(94.1)$ & $0(0)$ & $0(0)$ \\
\hline${ }^{\mathrm{b}}$ Group 2 & N (\%) & $1(1.1)$ & $70(80.5)$ & $1(1.1)$ & $15(17.2)$ \\
\hline${ }^{c}$ Group 3 & N (\%) & $0(0)$ & $37(77.1)$ & $1(2.1)$ & $10(20.8)$ \\
\hline
\end{tabular}

a: full recovery equal or less than one week

b: full recovery more than one week but equal or less than one month

c: full recovery more than one month

*ECT Electroconvulsive therapy

patients were exposed to the substance for a longer period or a larger dose of the substance.

Intimate Partner Violence (IPV) is a form of domestic violence in which the spouse will be a target for physical, and psychological, economic and sexual harm [18]. Regarding the particular symptoms of this disorder such as paranoia, and delusions of infidelity, it is assumed that these symptoms can make for intimate partner violence.

There is a high rate of IPV in certain groups of the society, including substance abusers, especially methamphetamine abusers [19-23]. However, in our study, only sever physical violence was studied, which calls for further research. In the present study, three-thirds of those sampled displayed at least one form of violence (toward the spouse, family, and society), and $61.2 \%$ of them met the criteria for severe physical IPV. Although our descriptive study may not be able to demonstrate a causal relationship between methamphetamine abuse and violent behavior, due to exclusion criteria of our study, it can be concluded that the violent behaviors only emerge after having abused methamphetamine. McKetin et al. [17] have reported that there is a clear increase in violent behaviors among methamphetamine abusers compared to when they do not abuse the substance. The findings of the present study indicate that there is a significantly high rate of physical violence in MIP inpatients. Special attention must be paid to the spouses and children of the married patients, and parents and siblings of the single patients who spend many days with the methamphetamine-addicted patients, and consequences of violence such as depression, anxiety and post-traumatic stress disorder should be explored [24, 25]. Unfortunately, admissions in the psychiatric hospitals in Iran mainly focus on removing psychiatric symptoms until the patient leaves the hospital, and do not much focus on the impact of the illness on the family members. It seems that the facilities available now may not be suitable or efficient enough.

Persistent psychosis has only been mentioned in the published works of East Asian researchers. In recent clinical studies, such as those done by Grelotti DJ et al. [12], more attention has been paid to studies in the East Asia. These studies have accepted that persistent psychosis can still emerge after methamphetamine abuse [12].
Published works of Iranian researchers in recent years confirm such a claim too $[11,14]$. There is a growing belief that adequate amounts and the period of methamphetamine abuse, without any special psychiatric history, can lead to MIP due to damage caused to Dopaminergic, Serotoninergic, and Noradrenergic cells [26-29]. Medhus et al. [30] found that among the patients with MIP, one third was diagnosed with schizophrenia during a 6 -year follow up. In a similar study in Thailand, $38 \%$ of MIP cases were given a diagnosis of schizophrenia, 6-years after their hospitalization [31]. Niemi-Pyntarri et al. [32] reported that the 8-year cumulative risk to receive a schizophrenia spectrum diagnosis was $30 \%$ for MIP patients. This has been argued for using MIP as a model for primary psychotic disorders and schizophrenia [33].

Despite the widespread abuse of methamphetamine and the related psychosis, there is no structured guideline for treating the MIP. The number of clinical trials has been too low to help formulate a comprehensive manual to be used by the therapists [3438]. In the present study, Risperidone and Olanzapine had the highest frequency of use of all antipsychotics, which can partly be the result of the current clinical trials indicating the positive effects of Risperidone in treating MIP [39]. These drugs are effective in restoring the weight, which patients considerably lost because of methamphetamine-induced appetite loss and hyperactivity. Almost all the patients in group1 received antipsychotic drugs. The overall approach is supportive treatment followed by the application of benzodiazepines in order to reduce restlessness and agitation [40]. Findings indicate that our therapists prefer the application of antipsychotics. The reasons may be the possibility of better control of violent behaviors, the therapist's expectation that the patients will not be classified in group 1, or the number of our hospital beds that is not proportionate to the number of patients. The one-week period within which the patients are not given antipsychotics can extend the length of hospitalization. In this approach, the clinician is not able to determine whether the patient responded to antipsychotics, or they recovered on their own, that can increase the risk of inappropriate use of antipsychotics. 
The recovery in $70 \%$ of the patients happened in less than a month, but at the end of the one month, at least $30 \%$ of the patients still had the symptoms. The application of ECT in group 2 aimed simply at controlling severe aggression and violent behaviors, thoughts of suicide and homicide. The ECT was applied for group 3, only when clinicians still detected persistent psychotic symptoms with no response to antipsychotics. The type of prescribed medication did not change during treatment with ECT in group 3. After 6 to 9 sessions of ECT, symptoms began to disappear. ECT helped improve psychotic symptoms alone or in combination with medication in nonresponsive-to-antipsychotic cases.

We did not come across any report of the application or effectiveness of ECT in treating MIP. It might seem that the application of ECT could be rather restricted in other countries. We found the only report of the effectiveness of ECT in treating MIP in a case study by Grelotti et al. [12]. Another reason might be that psychotic disorders exceeding more than one month, according to the American Psychiatric Association diagnostic criteria, are definitely considered primary psychiatric disorders [30-33], and therefore, the application of ECT in this case is allowed and effective. This reasoning rules out any such thing as persistent psychosis in the literature, let alone any treatment for it.

About $10 \%$ of the population in this study had suicidal thoughts one month prior to admission. Given the aggressive nature unique to these patients, in a hasty judgment, these patients are considered a source of aggression and hazard to other people. Additionally, compared to other psychiatric symptoms, suicide and self-aggression receive less attention. Methamphetamine abuse, in particular, has been followed by suicidal behaviors as well as fatal suicide attempts [41-47]. In blood and urine samples for toxicological analysis of suicide victims, alcohol and methamphetamine amounts were found to be significantly high [44]. In psychiatric emergency wards, the methamphetamine abusers are more likely to have experienced suicide attempts compared to other groups of inpatients [48].

Marshall and Werb [49] considered suicide and methamphetamine overdose as the main cause of death among adolescents and young adults abusing methamphetamine. It seems that the psychiatric symptoms of methamphetamine abusers along with depression may have contributed to this tendency [44, 45]. Many of participants in methamphetamine-related treatment programs suffer from depression [45, 46, 49]. The admissions in hospitals or the sudden intervals of substance withdrawals can be followed by depression and serious thoughts of suicide [50-55]. Thoughts of suspicion and constant thoughts of infidelity toward the spouse and feelings of fear and confusion over being always stalked can cause such feelings of helplessness in the patient of which, they begin to believe; only death can get them relieved. In addition, in the periods of intoxication, an increase in substance-related agitation and visual hallucinations were followed by a rise in the risk of suicide attempts $[43,44]$.

Homicide is the endpoint of violent behavior. Physical violent behavior can easily turn into homicide. Certain homicide attempts might result from the individual's violent behavior and not prior intentions, or might follow other dominant thoughts of homicide. In a study, the risk of homicide by a methamphetamine abuser was estimated to be 9 times that by the control group. Methamphetamine seems to be the only substance with such a strong link with homicide [22].

There are some limitations for this study. First, this study mainly focused on recovery from the positive symptoms. What we expect to see in the long-term clinical course are spontaneous relapses and negative psychotic symptoms, which could be induced by neurotoxic and degenerative effects of the substance on nerve pathways. Second, only severe physical violence has been taken into account and other important types of violence have not been considered. Third, this study was descriptive with a local focus; therefore, further analytical research on other forms of violence with a national focus seems necessary. Fourth, although we have a remarkable number of psychiatrists and mental health professionals and trained general practitioners in mental health system in Guilan, but we do not have any structured program for detecting people in early stages of developing psychosis or schizophrenia. It is not clear whether methamphetamine acts as a trigger for the first episode of psychosis in vulnerable people, or whether it starts an independent neuropathologic process.

\section{Conclusion}

The violence in these patients is significant and highly frequent. The frequency of persistent psychosis is 3 times the previous study in Iran, and closer to the statistics of the methamphetamine epidemics in Japan, indicating that the recovery time from psychotic symptoms is becoming longer in Iran, which agrees with many other studies suggesting that recovery from MIP can take more than a month. There were initial promising findings regarding the efficacy of treatment with electroconvulsive therapy, especially in treating persistent psychosis or reducing violent behaviors. In summary, the data present in this study can act as a motive to draw more attention to the harmful aspects of methamphetamine abuse in the Iranian society, especially regarding psychological health and social crimes. The results of this study are a serious warning, which calls for attention from psychiatrists and judicial authorities in devising proper preventive measures. 


\section{Abbreviations}

IPV: Intimate partner violence; MIP: Methamphetamine induced psychosis; ECT: Electroconvulsive therapy; BPRS: Brief psychiatric rating scale; DSMIV-TR: Diagnostic and statistical manual of mental disorders. 4th edition. Text revision.

\section{Competing interests}

The authors declare that they have no competing interests.

\section{Authors' contributions}

MK participated in the data interpretation and analysis and also in designing the study and drafting the manuscript. $\mathrm{HZ}$ carried out the patient assessment for inclusion and exclusion criteria and participated in the design of study and helped to draft the manuscript. $\mathrm{AH}$ and RA and $\mathrm{MZ}$ participated in data acquisition and helped to draft the manuscript. All authors read and approved the final manuscript.

\section{Acknowledgments}

This research was supported in part by grants from the Guilan University of Medical Sciences. We would like to express our thanks to Latifi and Moghaddam for proofreading, Seidpishe and Zare for statistical analysis, Dr Mohammadi and colleagues at the laboratory, and all the personnel in wards 3 and 7 and the psychiatric emergency ward at Shafa Hospital.

Received: 14 September 2015 Accepted: 12 February 2016 Published online: 25 February 2016

\section{References}

1. Zarghami M. Methamphetamine has changed the profile of patients utilizing psychiatric emergency services in Iran. Iran J Psychiatry Behav Sci. 2011;5:1-5.

2. Mehrjerdi ZA, Noroozi A. Methamphetamine intoxication in emergency departments of hospitals in Iran: implications for treatment. Iran J Med Sci. 2013;38(4):347-8.

3. Shariatirad S, Maarefvand M, Ekhtiari $\mathrm{H}$. Emergence of a methamphetamine crisis in Iran. Drug Alcohol Rev. 2012;32:223-4.

4. Lecomte T, Mueser KT, MacEwan W, Thornton AE, Buchanan T, Bouchard V, et al. Predictors of persistent psychotic symptoms in persons with methamphetamine abuse receiving psychiatric treatment. J Nerv Ment Dis. 2013;201(12):1085-9

5. Plüddemann A, Dada S, Parry CD, Kader R, Parker JS, Temmingh H, et al. Monitoring the prevalence of methamphetamine-related presentations at psychiatric hospitals in Cape Town, South Africa. Afr J Psychiatry. 2013;16(1):45-9.

6. Fasihpour B, Molavi S, Shariat SV. Clinical features of inpatients with methamphetamine induced psychosis. J Ment Health. 2013;22(4):341-9.

7. Yui K, Ikemoto S, Ishiguro T, Goto K. Studies of amphetamine or methamphetamine psychosis in Japan: relation of methamphetamine psychosis to schizophrenia. Ann N Y Acad Sci. 2000;914:1-12.

8. Yui K, Ikemoto S, Goto K, Nishijima K, Yoshino T, Ishiguro T. Spontaneous recurrence of methamphetamine-induced paranoid-hallucinatory states in female subjects: susceptibility to psychotic states and implications for relapse of schizophrenia. Pharmacopsychiatry. 2002;35(2):62-71.

9. Bramness JG, Gundersen $\varnothing \mathrm{H}$, Guterstam J, Rognli EB, Konstenius M, Løberg EM, et al. Amphetamine-induced psychosis-a separate diagnostic entity or primary psychosis triggered in the vulnerable? BMC Psychiatry. 2012;12:221.

10. Yui K, Ishiguro T, Goto K, Ikemoto S, Kamata Y. Spontaneous recurrence of methamphetamine psychosis: increased sensitivity to stress associated with noradrenergic hyperactivity and dopaminergic change. Eur Arch Psychiatry Clin Neurosci. 1999;249(2):103-11.

11. Mehrjerdi ZA. A brief overview of methamphetamine use treatment in Iran: Intervention and practice. J Res Med Sci. 2013;18(12):1018-20.

12. Grelotti DJ, Kanayama G, Pope Jr HG. Remission of persistent methamphetamine-induced psychosis after electroconvulsive therapy: presentation of a case and review of the literature. Am J Psychiatry. 2010; 167(1):17-23.

13. McKetin R, McLaren J, Lubman DI, Hides L. Hostility among methamphetamine users experiencing psychotic symptoms. Am J Addict. 2008;17(3):235-40.

14. Mehrjerdi ZA, Barr AM, Noroozi A. Methamphetamine-associated psychosis: a new health challenge in Iran. Daru. 2013;21(1):30.
15. Srisurapanont M, Ali R, Marsden J, Sunga A, Wada K, Monteiro M. Psychotic symptoms in methamphetamine psychotic in-patients. Int J Neuropsychopharmacol. 2003;6(4):347-52.

16. Srisurapanont M, Arunpongpaisal S, Wada K, Marsden J, Ali R, Kongsakon R. Comparisons of methamphetamine psychotic and schizophrenic symptoms: a differential item functioning analysis. Prog Neuropsychopharmacol Biol Psychiatry. 2011;35(4):959-64

17. McKetin R, Lubman DI, Najman JM, Dawe S, Butterworth P, Baker AL. Does methamphetamine use increase violent behaviour? Evidence from a prospective longitudinal study. Addiction. 2014;109(5):798-806.

18. Straus H, Cerulli C, McNutt LA, Rhodes KV, Conner KR, Kemball RS, et al. Intimate partner violence and functional health status: associations with severity, danger, and self-advocacy behaviors. J Womens Health (Larchmt). 2009;18(5):625-31

19. Cartier J, Farabee D, Prendergast ML. Methamphetamine use, self-reported violent crime, and recidivism among offenders in California who abuse substances. J Interpers Violence. 2006;21(4):435-45.

20. Ernst AA, Weiss SJ, Enright-Smith S, Hilton E, Byrd EC. Perpetrators of intimate partner violence use significantly more methamphetamine, cocaine, and alcohol than victims: a report by victims. Am J Emerg Med. 2008;26(5):592-6.

21. Martin I, Palepu A, Wood E, Li K, Montaner J, Kerr T. Violence among streetinvolved youth: the role of methamphetamine. Eur Addict Res. 2009;15(1):32-8.

22. Stretesky PB. National case-control study of homicide offending and methamphetamine use. J Interpers Violence. 2009;24(6):911-24.

23. Cohen JB, Dickow A, Horner K, Zweban JE, Balabis J, Vandersloot D, et al. Methamphetamine dependence. Am J Addict. 2003;12(5):377-85.

24. Coker AL, Davis KE, Arias I, et al. Physical and mental health effects of intimate partner violence for women and man. Am J Prev Med. 2002;23:260-8.

25. Foran $\mathrm{HM}, \mathrm{O}^{\prime}$ Leary $\mathrm{KD}$. Alcohol and intimate partner violence: a metaanalytic review. Clin Psychol Rev. 2008;28(7):1222-34.

26. Riddle EL, Fleckenstein AE, Hanson GR. Mechanisms of methamphetamineinduced dopaminergic neurotoxicity. AAPS J. 2006;8(2):E413-8.

27. Leviel $\mathrm{V}$. Dopamine release mediated by the dopamine transporter, facts and consequences. J Neurochem. 2011;118(4):475-89.

28. Kita T, Miyazaki I, Asanuma M, Takeshima M, Wagner GC. Dopamineinduced behavioral changes and oxidative stress in methamphetamineinduced neurotoxicity. Int Rev Neurobiol. 2009:88:43-64.

29. Cruickshank CC, Dyer KR. A review of the clinical pharmacology of methamphetamine. Addiction. 2009:104(7):1085-99.

30. Medhus S, Rognli EB, Gossop M, Holm B, Mørland J, Bramness JG. Amphetamine-induced psychosis: Transition to schizophrenia and mortality in a small prospective sample. Am J Addict. 2015;24(7):586-9. doi:10.1111/ ajad.12274.

31. Kittirattanapaiboon $P$, Mahatnirunkul $S$, Booncharoen $H$, Thummawomg $P$,

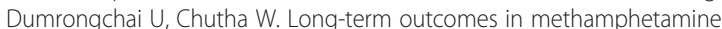
psychosis patients after first hospitalisation. Drug Alcohol Rev. 2010;29(4): 456-61. doi:10.1111/j.1465-3362.2010.00196.x.

32. Niemi-Pynttäri JA, Sund $R$, Putkonen $H$, Vorma $H$, Wahlbeck $K$, Pirkola SP. Substance-induced psychoses converting into schizophrenia: a registerbased study of 18,478 Finnish inpatient cases. J Clin Psychiatry. 2013;74(1): e94-9. doi:10.4088/JCP.12m07822.

33. Bramness JG, Gundersen $\varnothing \mathrm{H}$, Guterstam J, Rognli EB, Konstenius M, Løberg $E M$, et al. Amphetamine-induced psychosis-a separate diagnostic entity or primary psychosis triggered in the vulnerable? BMC Psychiatry. 2012;12:221. doi:10.1186/1471-244X-12-221.

34. Rawson RA, Gonzales R, Brethen P. Treatment of methamphetamine use disorders: an update. J Subst Abuse Treat. 2002;23(2):145-50.

35. Haile CN, Kosten TR, Kosten TA. Pharmacogenetic treatments for drug addiction: cocaine, amphetamine and methamphetamine. Am J Drug Alcohol Abuse. 2009:35(3):161-77.

36. Brensilver M, Heinzerling KG, Shoptaw S. Pharmacotherapy of amphetamine-type stimulant dependence: an update. Drug Alcohol Rev. 2013:32(5):449-60

37. Sulaiman AH, Gill JS, Said MA, Zainal NZ, Hussein HM, Guan NC. A randomized, placebo-controlled trial of aripiprazole for the treatment of methamphetamine dependence and associated psychosis. Int J Psychiatry Clin Pract. 2013:17(2):131-8.

38. Seddigh R, Keshavarz-Akhlaghi AA, Shariati B. Treating methamphetamineinduced resistant psychosis with clozapine. Case Rep Psychiatry. 2014;2014 845145 . 
39. Farnia V, Shakeri J, Tatari F, Juibari TA, Yazdchi K, Bajoghli $H$, et al. Randomized controlled trial of aripiprazole versus risperidone for the treatment of amphetamine-induced psychosis. Am J Drug Alcohol Abuse. 2014:40(1):10-5.

40. Winslow BT, Voorhees Kl, Pehl KA. Methamphetamine abuse. Am Fam Physician. 2007;76(8):1169-74

41. Chen CK, Lin SK, Chen YC, Huang MC, Chen TT, Ree SC, et al. Persistence of psychotic symptoms as an indicator of cognitive impairment in methamphetamine users. Drug Alcohol Depend. 2015;148:158-64.

42. Darke S, Kaye S, McKetin R, Duflou J. Major physical and psychological harms of methamphetamine use. Drug Alcohol Rev. 2008;27(3):253-62.

43. Glasner-Edwards S, Mooney LJ, Marinelli-Casey P, Hillhouse M, Ang A, Rawson R. Methamphetamine Treatment Project. Identifying methamphetamine users at risk for major depressive disorder: findings from the methamphetamine treatment project at three-year follow-up. Am J Addict. 2008;17(2):99-102.

44. Callor WB, Petersen E, Gray D, Grey T, Lamoreaux T, Bennett PJ. Preliminary findings of noncompliance with psychotropic medication and prevalence of methamphetamine intoxication associated with suicide completion. Crisis. 2005;26(2):78-84.

45. Kuo CJ, Tsai SY, Liao YT, Conwell Y, Lin SK, Chang CL, et al. Risk and protective factors for suicide among patients with methamphetamine dependence: a nested case-control study. J Clin Psychiatry. 2011;72(4):487-93.

46. Wang LJ, Chiang SC, Su LW, Lin SK, Chen CK. Factors associated with drugrelated psychiatric disorders and suicide attempts among illicit drug users in Taiwan. Subst Use Misuse. 2012:47(10):1185-8.

47. Lingamfelter DC, Duddlesten E, Quinton RA. An unusual suicidal death by automobile antenna: a case report. Diagn Pathol. 2009:4:40.

48. Pasic J, Russo JE, Ries RK, Roy-Byrne PP. Methamphetamine users in the psychiatric emergency services: a case-control study. Am J Drug Alcohol Abuse. 2007;33(5):675-86.

49. Marshall BD, Werb D. Health outcomes associated with methamphetamine use among young people: a systematic review. Addiction. 2010;105(6):991-1002. Review.

50. Glasner-Edwards S, Marinelli-Casey P, Hillhouse M, Ang A, Mooney LJ, Rawson R. Methamphetamine Treatment Project Corporate Authors. Depression among methamphetamine users: association with outcomes from the Methamphetamine Treatment Project at 3-year follow-up. J Nerv Ment Dis. 2009;197(4):225-31.

51. McKetin R, Lubman DI, Lee NM, Ross JE, Slade TN. Major depression among methamphetamine users entering drug treatment programs. Med J Aust. 2011;195(3):S51-5.

52. Cloutier RL, Hendrickson RG, Fu RR, Blake B. Methamphetamine-related psychiatric visits to an urban academic emergency department: an observational study. J Emerg Med. 2013;45(1):136-42.

53. Glasner-Edwards S, Mooney LJ, Marinelli-Casey P, Hillhouse M, Ang A, Rawson $R$, et al. Risk factors for suicide attempts in methamphetamine-dependent patients. Am J Addict. 2008;17(1):24-7.

54. Zweben JE, Cohen JB, Christian D, Galloway GP, Salinardi M, Parent D, et al. Psychiatric symptoms in methamphetamine users. Am J Addict. 2004;13(2): 181-90.

55. Kalechstein AD, Newton TF, Longshore D, Anglin MD, van Gorp WG, Gawin $\mathrm{FH}$. Psychiatric comorbidity of methamphetamine dependence in a forensic sample. J Neuropsychiatry Clin Neurosci. 2000;12(4):480-4.

\section{Submit your next manuscript to BioMed Central and we will help you at every step:}

- We accept pre-submission inquiries

- Our selector tool helps you to find the most relevant journal

- We provide round the clock customer support

- Convenient online submission

- Thorough peer review

- Inclusion in PubMed and all major indexing services

- Maximum visibility for your research

Submit your manuscript at www.biomedcentral.com/submit

) Biomed Central 